\title{
An Impact of Management Information Systems on Corporate Sustainability: A Survey
}

\author{
Srinivas Nowduri ${ }^{1}$ \\ 1 Department of Information Technology and Computer Science, American University of Afghanistan, \\ Afghanistan \\ Correspondence: Srinivas Nowduri, Department of Information Technology and Computer Science, American \\ University of Afghanistan, Darul Aman Road, Kabul, Afghanistan. E-mail: snowduri@auaf.edu.af or \\ drnsrini@gmail.com
}

Received: March 31, 2014

doi:10.5539/ijbm.v9n7p146
Accepted: April 21, 2014

Online Published: June 22, 2014

URL: http://dx.doi.org/10.5539/ijbm.v9n7p146

\begin{abstract}
Management information systems and its significance and impact in today's corporate world are determined based on several factors pertaining to sustainability and green revolution. A framework for the competency model among the sustainable corporation is outlined. Management information system and its impact on the corporate world are detailed; along with a framework of modern view of corporate sustainability is explained. Finally as theoretical contributions of this work, proposed four schools of thought for today's business organization to remain sustainable.
\end{abstract}

Keywords: information systems, corporate, sustainability

\section{Introduction}

In this era all business functionalities (internal as well as external) of a business organization is invariably depends on storage, retrieving and manipulating the available 'information' with the help of certain computer based systems. Start from gathering the requirements, till the product delivery via production process, are centrally controlled by certain computer systems. Thereby every business operation in major business organizations is invariably under the control of automation systems. Management information system (MIS) is one such computer based (business specific) information system used to store and retrieves business related information; further it helps meeting the organizational strategic and tactical business goals. In recent decades, MIS is start acting as an entity for set of businesses and resources that are used to pull together information from the corporate functional and tactical systems (Laudon \& Laudon, 2009; Saleh, 2010). This makes MIS to accept data from different levels of management (such as executive, supervisory and operational) within the business organization, for their right actions and business directions.

When every business organizations slowly and solely start depending on several business functional systems, there is a wide scope for their growth in term of business sustainability. For example, customer relationships management (CRM) combines data that relates to customer experience, accumulates data from existing and new customers. An enterprise resource planning system (ERP) combines data used in the entire sales process, where marketing strategies and projections are vital. Decision support system (DSS) and data warehouse system (DWS) combines data from multiple systems in order to show an over view of the entire organization.

By design and functional nature MIS is not necessarily a functional system, but it is designed based on various business needs, by combining information from multiple systems. These systems help managers in better understanding the progress of various departments within their organization. Eventually all these systems gives an insight about appropriate actions required for various departments, customer needs, and help both management and employees' professional development.

In recent years, MIS has also become a vital force for corporate efficiency with its seminal attempt in improving the business quality and productivity. The corporate world on the other hand, is continuously start depending on automation of their major business activities such as operational, manufacturing and managerial activities, to meet its strategic business goals; known to be the corporate sustainability. Thus the "corporate sustainability" is quickly encompasses certain strategies and business practices to meet the needs of today's stockholders, with 
protecting and enhancing the human and natural resources needed in the future (Epstein \& Roy, 2001; Oliver et al., 2005; Shepherd, Kuskova, \& Patzelt, 2009).

This research sheds light on past and current status of corporate sustainability and its influencing factors, along with the impact and role of MIS in attaining such business goals. This works also defines a framework for competency model among the sustainable corporations. Finally defines different schools of thoughts for modern corporate sustainability.

The objectives and uniqueness of this research work is point focus towards MIS and its support to modern businesses. This is especially viewed as a supporting information system (for rapidly changing market technology) and a supporting tool for corporate sustainability. The uniqueness of this research work is of twofold: It contribute theoretical basis for young entrepreneurs towards sustainability and usage of MIS. Secondly, the proposed schools of thought can be incorporated into the MIS design for a better assistance towards business improvement in this modern era.

\section{MIS and Corporate Sustainability: A Brief Review}

Modern corporate culture and competitive market has revealed two seminal facts: (1) extensive usage of computer based system and; (2) significance of corporate sustainability facts (Allen, Heurtebise, \& Turnbull, 2010; UStudy, 2010). Usage of computer based systems (such as MIS, DSS and EIS) is also coupled with networking technology within the corporate business activities results in business improvement from several perspectives viz., employee-employer relation map, sustainability issues and employees' professional development. This section is focus on the MIS and corporate sustainability, to demonstrate more on the environmental responsibility within a business organization. This can take care of variety of actions pertaining to corporate sustainability (and nature) such as (Benerjee et al., 2003; Epstein \& Roy, 2001). (a) steps to reduce, recycle, and reuse raw materials and waste materials, (b) minimizing the impact of transportation and (c) adopting formal environmental policy in reducing the pollution and (d) optimal usage of energy and water by the corporation.

Corporate sustainability performance can be visualized as an investable concept, which comes hand in hand with several business professional groups, within and across the business units in an organization [1]. This has slowly become a crucial business strategy that drives business interest and investments in sustainability, which mutually benefits both companies and investors. As this benefit to business group with circle strengthens, it will have a positive effect on the societies, where the business organization located (Oliver et al., 2005). Therefore it boosts the economies of both the developed and developing nations around the world.

Corporate sustainability is also strongly intertwined link and roots with customer relationship management (CRM). In this era, with increase trends towards customer relationship and customer experience management, corporate units start thinking in establishing a solid (long-term) base for consumer employee value by adopting natural environment. Corporate sustainability thus makes all the business operation trends fine-tuning towards social, cultural and economic environment. This view point possesses a direct impact on the corporation's long term viable progress (Nowduri, 2011). At the same time this sheds more light on the transparency of business management/operations and help improving the employee professional development. Finally this is expected is to uplift corporate ethical practices in a positive direction.

From the implementation perspective, corporate sustainability is considered to be the corporate responses to sustainable development. Corporations in this modern era start operate their businesses, from two different perspectives: environmental and social matters. For example, the environmental issues include climate change energy efficiency, use of natural resources, and social issues such as corporate ethics, work place diversity, and vendor management. Thereby corporate sustainability has become a vital issue in view of maintaining confidence of their investors, business partners, customers and employees. The following are some of the salient features of corporate sustainability (Oliver et al., 2005; Allen, Heurtebise, \& Turnbull, 2010; Basu, Osland, \& Solt, 2008):

- Improvement of business strategies and practices;

- Creating an eco-friendly work environment within and across organizations;

- Creating and developing products and services which do not create any atmospheric pollution, reduced distribution cost, use of renewable energy, etc.

- Developing products and services, which creates long term shareholder value and sustainable development;

- Improving the technological capabilities, that respect environment by reducing the emission of greenhouse gases, cooperating with risk management systems, etc.

Past literature has clearly indicates that MIS as a helping hand to the corporate world ever since its inception as an 
emerging supporting software tool for corporate decision making, at different levels across the organization. At the same time, in various business activities MIS is also used for determining the amount of raw material needed for manufacturing products. For example, cement industry uses different raw materials such as lime stone, sand, and few chemicals as ingredients, in a proper proportion. In manufacturing industry as well MIS is very useful for determining the precision and accuracy of the products. For example, in TV picture tubes manufacturing cathode rays, deflection coils, phosphorous, etc. as ingredients, where manufacturing according to the specific design needs to be monitored. Overall the existing MIS are aimed at automating several corporate routine activities, decision making, ultimately help optimizing the time and increase the accuracy, leading to the corporate sustainability ( Saleh, 2010; Shepherd, Kuskova, \& Patzelt, 2009; Tolentino, 2012).

In recent days with the increase of technology and awareness towards sustainability with in the corporate world, the business organizations start adopting MIS as part of their business process. The design and development of modern MIS are fine-tuned in such a way that they are more susceptible towards sustainability; in view of safe transfer of business activities to the next generation. This has surfaces one seminal fact: every corporate business goal is invariably intertwined with the existing social and environment nature, in which the corporate business operations work (Rhodes, 2010; Srinivas, 2012). It is also realized that some of the modern corporations that failure to realize sustainability (especially environments and social) issues are clearly impact their business practices, results only in short-term gains.

\section{MIS and the Competency among the Sustainable Corporations}

Modern corporate sector is directly or indirectly, start adopting new research practice and technologies exclusively to analyze and benchmarks global companies' initiatives focused on green and sustainable business practices. That means they are slowly start adopting their internal sustainability programs, such as green product initiatives, and environmental responsibility goals. As a result, the majorg sustainability companies start displaying high levels of competence in addressing global and industry challenges in a variety of areas as (Obasan \& Soyebo, 2012; Oliver et al., 2005; Basu, Osland, \& Solt, 2008):

- Strategy: This is a long term business plan to integrate economic, environmental and social aspects in their business strategies while maintaining global competitiveness and brand reputation.

- Financial: This is a trade-off between demand, supply and systems support. At times, meeting shareholders' demands for (a) sound financial returns, (b) long-term economic growth, (c) open communication and (d) transparent financial accounting.

- Customer \& Product: Fostering loyalty by investing in customer relationship management and product and service innovation that focuses on technologies and computer based systems, which use financial, natural and social resources in an efficient, effective and economic manner over the long-term.

- Governance and Stakeholder: Setting the highest standards of corporate governance and stakeholder engagement primarily includes corporate codes of conduct and public reporting.

- Human Resource Management: Managing human resources to maintain workforce capabilities and employee satisfaction through best-in-class organizational learning and knowledge management practices and remuneration and benefit programs.

It is very clear that, the competitive world is molding towards quick and efficient success in every business aspect. Thereby the business knowledge, working skills and the work group attributes, play an important role for business success (Al-Zhrani, 2010; Nowduri, 2011). At the same time, MIS is inter-twined with each of these components. Therefore competency has become a defined cyclic process for modern businesses, with high priority focus towards business "strategy", as shown Figure 01 below. This model primarily indicates the various components within corporate sustainability. This model needs to be further developed in view of MIS impact to reflect today's business. 


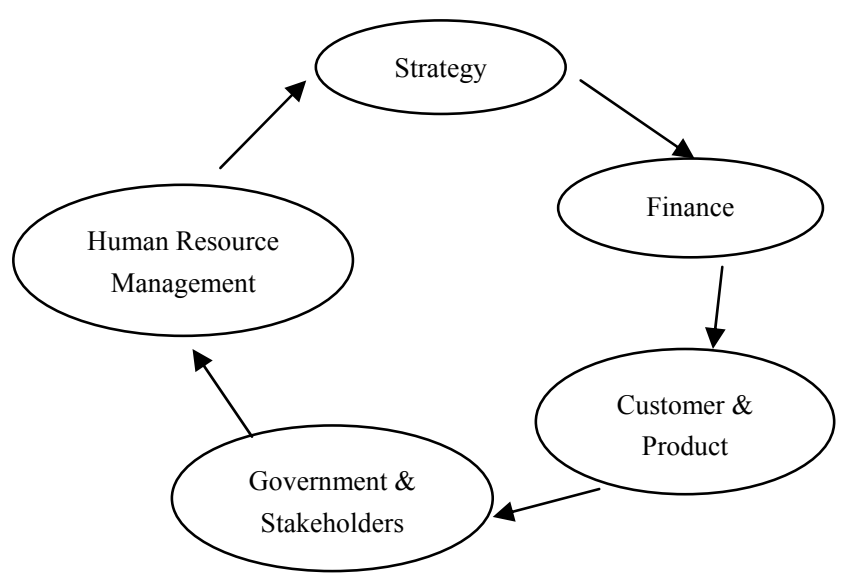

Figure 1. Competency model for sustainable corporations

This competency model is subject to the nature of business, and is well connected with several human resources management activities, which are beyond the scope of this work. Each of these components is well supported with appropriate MIS as a computation tool, detailed in the next section. This emphasizes the fact that corporate sustainability is within the grip of modern information systems, such as MIS - for better automation of certain organizational sub processes, and for integration.

\section{MIS as a Business Partner to Modern Corporate World}

Collecting, processing, storing and transmitting information in a corporate world are the primary capabilities of MIS, ever since its invention. These computer based systems has been in support for corporate management for intelligent decision making. In most of the modern business, each step in the above competency model is invariably connected with a computer based system like MIS. Further MIS is viewed as an integrated set of components which interacts with each other for better decision making and planning purpose, while meeting the business goals. In addition to this fact, technological evolution makes modern managers to access large amounts of data, and help solving complex tasks and support better decision making. Competency is another factor which triggers and moves corporate world, especially with the technological advancements. In this way, MIS is intertwined with competency framework in the corporate world, detailed in the next few sections.

Most of the modern businesses have been start leveraging MIS to manage order, organize and manipulate the gigabytes and masses of information generated for various business purposes, such as planning, processing, projecting, etc. MIS acts as an optimizing tool to help businesses, mainly in optimizing business processes, to address information needs of employees and various stakeholders and to take informed strategic decisions. At the same time, budget allocation and monitoring issues, at large corporate sectors, can affect the efficacy of MIS. This depends on coast effectiveness and functionality of MIS. Therefore MIS has its advantages and disadvantages that are primarily depend on organizational deployment and usage.

MIS is a computer based system or process that provides the information necessary to manage (at all levels) an organization more effectively than ever. In recent years, the MIS and the information it generates has become an essential components of prudent and reasonable business decisions (Al-Zhrani, 2010; Nowduri, 2011). MIS further possess a clear demarcation and definite framework of guidelines, policies or practices, standards, and procedures for a given organization, preserving the organization's long term strategic goals and objectives. The following are some of the MIS objectives that are likely impact corporate world (Al-Zhrani, 2010; Vittal \& Shivraj, 2008):

- To enhance communication among employees.

- To deliver complex material throughout the institution.

- To provide an objective system for recording and aggregating information.

- To reduce expenses related to labor-intensive manual activities.

- To support the organization's strategic goals and direction.

- To support business decision making process, as it provide organizational specific information to corporate managers. 
It is also worth noticing that MIS is capable of enhancing the job performance throughout business processes. At an executive level it provides information for making strategic decisions, measuring the quality and performance. Monitoring day to day activities at supervisory level for possible tactical decisions is a vital of MIS. Finally operational aspects are also monitored by MIS at low level management or working class. The concept of organizational and behavioral aspects of decision making by MIS, is clearly providing an insight in to the designers to handle the organizational culture and the constraints.

Overall MIS has become a monitoring and supporting tool helps management, employees and customers. Most of the modern MIS are automation and autonomous systems, meeting the organizational unique business goals and objectives. The following are some of the unique features of modern MIS (Rhodes, 2010; UStudy, 2010):

- Capability for assessing and managing the organizational risk and strategy

- Supports management's ability to performance reviews.

- Recognize, monitor, measure, limit, and manage business risks.

- Helps operational processes.

- Help staff and management, provide a possible feedbacks

In most of the modern businesses, it is difficult to demark between operational processes and their feedback systems/devices. Automation of most of the operational devices, is clearly giving less scope for any human errors. MIS being both operational as well as informational, it is vital for organizations to monitor the performance and manage resources, to remain and sustain in competitive market, apart from producing rich quality products. In spite of strict rules and regulation enforced in the organization's vision and mission statement, monitoring the performance at individual employees level as well as individual department (unit), will always help reducing the business risks.

The following are some of the significant facts of MIS in the modern era, for better business planning and to align a good strategic business direction (UStudy, 2010; Nowduri, 2011). We have further fine-tuned some of these facts within the purview of sustainability.

- It should be management oriented but strongly coupled with the concept of improving the employee-employer relation map;

- Organizational specific MIS should be in a position to integrate: (a) corporation and its customer base, (b) corporate business processes and employee professional development and (c) corporate business processes and sub-processes;

- Help all levels of management in decision making activity, viz., executives (strategic), supervisory (tactical) and low-level (operational);

- Should asses and project corporate's short-term and long-term plans, apart from (a) production and investment (b) sales and production;

- Should be in a position to draw graph among (a) business process and its deviations (b) each department (unit) and its performance.

In variably, most of the MIS are now only designed and developed for the purpose of quick, timely manner and for informed decision making. Surely many of them are very much useful in strategic business decision making. At the same time, it is worth noticing that, timely decision-making activity in any corporate business process has its own significance and vital role in overall organizational productivity and quality improvement (Vittal \& Shivraj, 2008).

\section{Corporate Sustainability in Technological Era}

The term sustainability can be defined in several ways by several authors, in simple term one can define it as a business approach that creates a long term shareholder value, improves business performance by removing waste and manages risk (Tolentino, 2012; Shepherd, Kuskova, \& Patzelt, 2009). It is further emphasizes that a strong link across economic, environmental and social issues, establishes strong corporate sustainability in the competitive market. For example, supply chain can have some liability and social issues in the case of a product of using hazardous chemicals. Improper disposal of company products and substances can be contaminated and can create long term environmental effects in any business organization. In spite of many consumer products being recycled contents and waste disposals, initially appears inexpensive, but can become more expensive causing economic viability. This is especially so due to eco-friendly packaging and environmental concerns. 
All these concerns make up the corporate world to have relooked into all its sustainability aspects and their own corporate sustainability. Thereby corporate sustainability is precisely making a tradeoff between the 'consumer demand' and 'eco-friendly products'. This looks pretty good for common man in the market. At the same time, this further stresses on regulating, handling and usage of hazardous material in the corporate world, in order to make a user-friendly environment and society. Thus in recent years, the very idea behind 'corporate sustainability' can be broadly stated as a combination of the following three facts:

1) It is a business approach that creates long-term consumer and employee value;

2) It is totally aimed towards the natural environment, including economic, cultural and social environments prevailing within the business organization;

3) It is also establishes the basis for ethical corporate practices.

Every corporate organization in this modern era is start assessing how financial, governance, environmental and social risk and opportunities interact for the long-term viability of their investment (Tolentino, 2012; UStudy, 2010; Epstein \& Roy, 2001). The primary aspects of any corporate sustainability include professional (work) transparency, employee professional development and effective usage of resources.

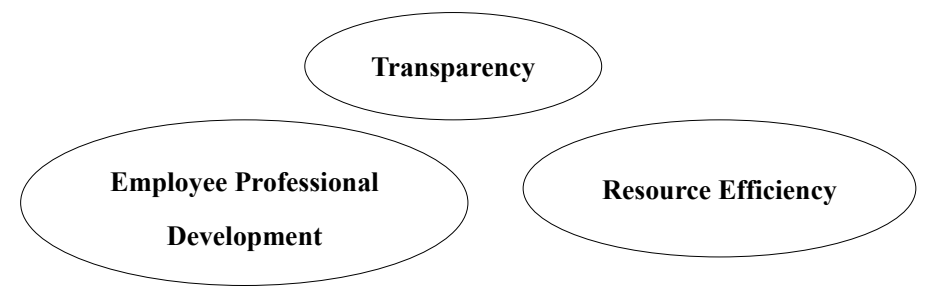

Figure 2. Basic elements of corporate sustainability

Transparency: This deals with the idea that by having an engaging and open environment within the company as well as the community will improve performance and increase profits. It is an open culture that promotes employee involvement in regards to the innovation and creative processes. Reaching out to the community creates a much bigger team, is extremely cheap, and provides evaluation from all angles. Companies are looking inward and realizing changes must be made to fulfill environment needs such as energy efficiency, limiting product waste and toxicity, and designing innovative products.

Changes to Transparency: In this modern era, apart from this open and community environment, one needs to consider the sustainability factors, such as renewable energy sources as well as reusable components. This creates the sustainability awareness within the purview of green revolution.

Employee professional development: For most of the corporate sector organizations people work in groups with varying experience levels. These are the most important renewable resource for the organization and therefore are the strongest assets. Any professional development program shed its light on these individuals, for their better performance. Therefore a strong development program could be the underlying factor for a company's success or failure. Employees are the concrete foundation for the company and must be thoroughly analyzed and evaluated to tap into their true motivations and desires. For a company that wants to reach its greatest potential, employees must work towards improvement rather than perfection. Programs should be implemented that rewards star performers, fosters the creative learning process, and provides comprehensive training and evaluating.

Changes to employee professional development: In this modern era, the aspects of employee's professional development, the first criterion is to consider employee's strategic plan and his/her thinking process. Added to this, the employee's careful, safe and smooth transfer of the organizational business process to the next generation, without altering its sustainability factors, needs to be smooth.

Resource efficiency: Most of the corporate sector companies in this decade are start adapting rapidly changing environment by being prepared to change and implement new creative ideas related to their company's sustainability. Companies should not throw away old products and materials, but rather be prepared with upgraded technology that can transform the product. New solutions that improve recycling and waste redirecting can ultimately reduce costs and increase profits. 
Changes to resource efficiency: In this modern era, these rapid changes and new criterion should point focus towards, volatile market trends coupled with corporate sustainability. This is especially so while upgrading to new technology, based on waste reduction criterion.

\section{Four Schools of Thought for Modern Corporate Sustainability}

In this technological era, every business corporation has many schools of thought, in establishing corporate sustainability. The basic idea is centered in establishing a long-term consumer and employee value. This is possible only through a strong strategy formation, implementation and validation. This can be achieved through four schools of thought as detailed below. We carefully formulated these four schools of thought as an aid in improving the modern corporate world. In turn these will have major impact exclusively on the employee's professional development that brings better business productivity and quality.

The first school of thought goes towards focusing on the fast growing competitive market trend (Nowduri, 2011). This school of thought towards corporate sustainability focuses on the prevailing competitive markets. One possible way of handling this: create a strong employee' professional development scheme. This view point is normally neglected by several small organizations as they look at quick return for their investments.

The second school of thought towards corporate sustainability is to fine tune the business towards natural environment. This needs to begin from supply chain (supply chain management) and end with consumer (customer relationship management) via employee and employer relation map. This basically for bring out sustainable products and services.

The third school of thought towards corporate sustainability is to coop-up with the rapidly changing market technology and its innovation. The fourth school of thought is focus towards establishing a strong collaboration (which is missing today) between

(a) Employee and employer

(b) Corporate rules and government regulations and

(c) Suppliers and corporate policies

We have developed the following model for efficient usage of MIS in maintaining sustainability issues within the modern corporate world. The six components like finance, strategy formation, customer product development, etc., were first analyzed and then use it for better decision-making. The following Figure 03 consolidates the views expressed in competency model coupled with the elements of corporate sustainability, leading to the modern corporate sustainability. It also expresses three seminal facts for modern corporate sustainability:

- Transparency in 'business strategy' and 'finance' is vital for modern corporate sustainability

- Employee professional development can lead to good customer and product quality apart from value addition to stakeholders.

- $\quad$ Resource efficiency can be achieved with better human resource management.

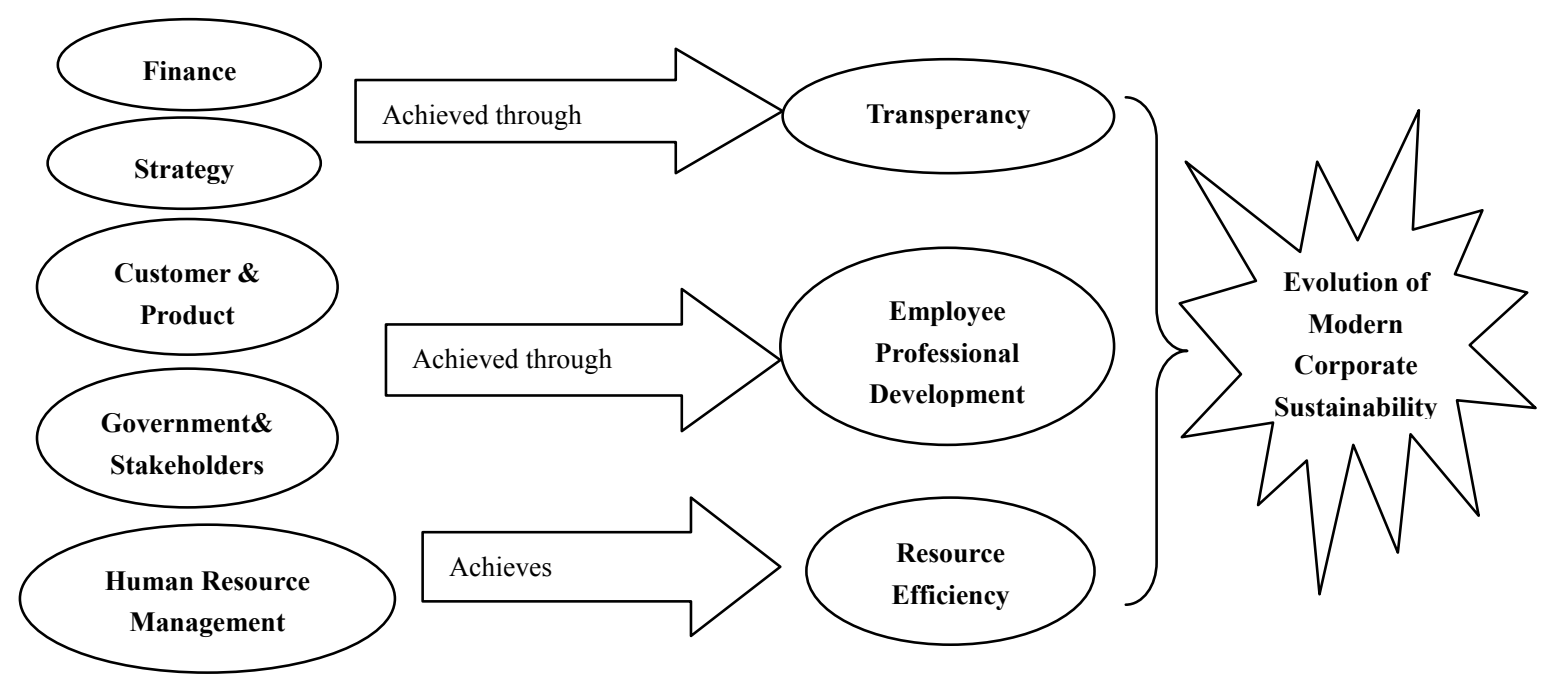

Figure 3. Evolution of modern corporate sustainability 
The practical contributions of this research can be briefly stated as following: Several researchers in the past were focus on sustainability issues via, business development or new course proposal for employees (Oliver et al., 2005; Saleh, 2010; Shepherd, Kuskova, \& Patzelt, 2009). This work can further enhance such vision via incorporating and injecting sustainability using MIS in to the business planning. This results in both enhancing competitive advantages as well as creates a proper road map for corporate leadership.

\section{Useful Conclusions and Future Possibilities}

It is concluded that modern MIS design and development has certain inbuilt capabilities to incorporate sustainability factors and so acts as a helping hand to corporate sustainability. It is concluded that every business corporation is transiting from strategy to sustainability, via social media to remain competitive. Furthermore formation of sustainability groups within the business corporations is vital for greater work commitment and help improving the cross-functional groups/departments. Since change in corporate management has significant impact on the MIS and its decision making capability, every business organization need to be flexible in feeding the data into MIS. To this effect, as a theoretical contribution of this work, four schools of thought for today's business organization are presented, to remain sustainable.

Currently the risk management issues may not be reflected properly by current MIS development. Therefore future research needs in two primary directions: (a) compatibility of organizational sustainability with risk management issues and (b) the fine tuning the corporate business strategy with corporate sustainability via employee awareness programs about sustainability using MIS.

\section{References}

Allen, B., Heurtebise, A., \& Turnbull, J. (2010). Improving Information Access. Business Management US. Retrieved from http://www.busmanagement.com/article/Improving-information-access/

Al-Zhrani, S. (2010). Management information systems role in decision-making during crises: case study. Journal of Computer Science, 6(11), 1247-1251. http://dx.doi.org/10.3844/jcssp.2010.1247.1251

Basu, A., Osland, A., \& Solt, M. (2008). A New Course on Sustainability Entrepreneurship. Retrieved from http://nciia.org/conf08/assets/pub/basu1.pdf

Benerjee et al. (2003). Corporate Environmentalism: Antecedents and Influence of Industry Type. Journal of Marketing, 67, 106-122. http://dx.doi.org/10.1509/jmkg.67.2.106.18604

Epstein, M. J., \& Roy, M. J. (2001). Sustainability in Action: Identifying and Measuring the Key Performance Drivers. Long Range Planning, 34, 585-604. http://dx.doi.org/10.1016/S0024-6301(01)00084-X

Laudon, K., \& Laudon, J. (2009). Management Information System (11th ed.). USA: Prentice Hall, New Jersey.

Nowduri, S. (2011). Management Information Systems and Business Decision Making: Review, Analysis and Recommendation. Journal of Management and Marketing Research, 7.

Obasan, K. A., \& Soyebo, Y. (2012). Management Information System as a Catalyst to Organizational Performance in the 21st Century: A Study of Selected Banks in Nigeria. American Journal of Business Management, 1(1).

Oliver et al. (2005). The Business Case for Corporate Sustainability: Literature Review and Research Options. Europe Management Journal, 23(1), 27-36. http://dx.doi.org/10.1016/j.emj.2004.12.007

Rhodes, J. (2010). The Role of Management Information Systems in Decision Making. Retrieved from http://www.ehow.com/facts_7147006_role-information-systems-decision-making

Saleh, Al. Z. (2010). Management Information Systems Role in Decision-Making During Crisis: Case Study. Journal of Computer Science, 6(11).

Shepherd, D. A., Kuskova, V., \& Patzelt, H. (2009). Measuring the values that underline Sustainable Development: The Development of Valid Scale. Journal of Economic Psychology, 30, 246-256. http://dx.doi.org/10.1016/j.joep.2008.08.003

Srinivas, N. (2012). Management information systems and its support to small and medium enterprises owners. Proceeding of the society for advancement of management, International Business conference, Las Vegas.

Tolentino, A. (2012). NGOs and Business for Sustainable Development. Environmental Policy and Law, 42(1).

UStudy. (2010). MIS and decision making. Retrieved from http://www.ustudy.in/node/1009

Vittal, A., \& Shivraj, K. (2008). Role of IT and KM in improving project management performance. Vine, 38(3), 357-369. 


\section{Copyrights}

Copyright for this article is retained by the author(s), with first publication rights granted to the journal.

This is an open-access article distributed under the terms and conditions of the Creative Commons Attribution license (http://creativecommons.org/licenses/by/3.0/). 